\title{
Dynamics of the thalamo-cortical system driven by pulsed sensory stimulation
}

\author{
Arne Weigenand ${ }^{1,2^{*}}$, Michael Schellenberger Costa ${ }^{1}$, Hong-Viet Ngo ${ }^{4}$, Lisa Marshall ${ }^{3}$, Thomas Martinetz ${ }^{1}$ \\ Jens Christian Claussen ${ }^{1,2}$ \\ From Twenty Second Annual Computational Neuroscience Meeting: CNS*2013 \\ Paris, France. 13-18 July 2013
}

There exists a large body of evidence pointing to an essential role of sleep in memory consolidation [1-3]. In particular non-REM sleep seems to be important for consolidating declarative memories [4]. Boosting the socalled slow oscillations $(<1 \mathrm{~Hz})$ during non-REM sleep via transcranial electric stimulation leads to a potentiation of memory [5]. It has also been demonstrated that slow oscillations can be induced by optogenetic, magnetic and acoustic stimulation [6-8]. Here we present data from human sleep studies and modeling results on the thalamo-cortical system under sensory stimulation, that give new clues for effective stimulation protocols. We use a population model that exhibits important features of brain activity during non-REM sleep, e.g. spindles, cortical

Slow oscillations with gamma activity and clock-like delta oscillations. The model aims at reproducing evoked responses of auditory and visual stimuli at several frequencies. We extend previous results on the phasedependent response of isolated cortex [9] to stimuli which are time-locked to spindle and slow oscillation events and test the hypothesis that the main factor determining thalamic gating properties in non-REM sleep is the phase of the cortical slow oscillation.

\section{Author details}

'Institute for Neuro- and Bioinformatics, University of Lübeck, 23562 Lübeck, Germany. ${ }^{2}$ Graduate School for Computing in Medicine and Life Sciences, University of Lübeck, 23562 Lübeck, Germany. ${ }^{3}$ Department of Neuroendocrinology, University of Lübeck, 23562 Lübeck, Germany. ${ }^{4}$ Institute of Medical Psychology and Behavioral Neurobiology, University of Tübingen, 72074 Tübingen, Germany.

\footnotetext{
* Correspondence: weigenand@inb.uni-luebeck.de

'Institute for Neuro- and Bioinformatics, University of Lübeck, 23562 Lübeck, Germany

Full list of author information is available at the end of the article
}

Published: 8 July 2013

\section{References}

1. Stickgold R: Sleep-dependent memory consolidation. Nature 2005, 437(7063):1272-1278.

2. Diekelmann S, Born J: The memory function of sleep. Nat Rev Neurosci 2010, 11(2):114-126.

3. Marshall L, Born J: The contribution of sleep to hippocampus-dependent memory consolidation. Trends Cogn Sci 2007, 11(10):442-450.

4. Plihal W, Born J: Effects of early and late nocturnal sleep on declarative and procedural memory. J Cognitive Neurosci 1997, 9(4):534-547.

5. Marshall L, Helgadottir H, Mölle M, Born J: Boosting slow oscillations during sleep potentiates memory. Nature 2006, 444(7119):610-613.

6. Massimini M, Ferrarelli F, Esser SK, Riedner BA, Huber R, Murphy M, Peterson MJ, Tononi G: Triggering sleep slow waves by transcranial magnetic stimulation. Proc Natl Acad Sci USA 2007, 104(20):8496-8501.

7. Kuki T, Ohshiro T, Ito S, Ji Z, Fukazawa Y, Matsuzaka Y, Yawo H, Mushiake H: Frequency-dependent entrainment of neocortical slow oscillation to repeated optogenetic stimulation in the anesthetized rat. Neurosci Res 2012.

8. Ngo HW, Claussen JC, Born J, Mölle M: Induction of slow oscillations by rhythmic acoustic stimulation. J Sleep Res 2013, 22:22-31.

9. Weigenand A, Martinetz T, Claussen JC: The phase response of the cortical slow oscillation. Cogn Neurodyn 2012, 6(4):367-375.

doi:10.1186/1471-2202-14-S1-P67

Cite this article as: Weigenand et al: Dynamics of the thalamo-cortical system driven by pulsed sensory stimulation. BMC Neuroscience 2013 14(Suppl 1):P67.

\section{Submit your next manuscript to BioMed Central} and take full advantage of:

- Convenient online submission

- Thorough peer review

- No space constraints or color figure charges

- Immediate publication on acceptance

- Inclusion in PubMed, CAS, Scopus and Google Scholar

- Research which is freely available for redistribution

\section{() Biomed Central}

